\title{
AC 2007-2684: ASSESSING BOTH TECHNICAL AND ARTISTIC SKILLS IN DIGITAL MEDIA COURSES WITHIN A TECHNOLOGY PROGRAM
}

\section{Cher Cornett, East Tennessee State University}

Cher Cornett, Associate Professor, is the Director of the Niswonger Digital Media Center at East Tennessee State University. She has worked professionally as a graphic designer and illustrator for over 25 years and has been involved in developing interactive multimedia products for over 16 years, including pioneering work in interactive instructional product design at Florida State University. Prior to coming to ETSU, she coordinated the Interactive Multimedia Masters Degree Program at Southern Illinois University; chaired the Graphic Arts Technology program at State Technical Institute at Memphis where she built one of the first interactive multimedia programs in a 2-year college; and owned and operated CC Design, a design and multimedia studio in

Tallahassee, FL. Her research interests include computer-based interactive instruction for K-12, digital storytelling, curriculum design in digital media, and interactive multimedia art.

Cornett has won numerous awards for design, illustration and interactive media, including Best of Show honors in the ADDY competitions. She is a registered Judge for the American Advertising Federation, and serves as a curriculum auditor for the Tennessee Board of Regents. 


\title{
Assessing Both Technical and Artistic Skills in Digital Media Courses within a Technology Program
}

\begin{abstract}
Digital media courses are usually found in art or communications departments where the instructional emphasis is weighted toward artistic and creative aspects of project development. In digital media courses offered in departments oriented to the technical professions, such as computer science and engineering technology, the instructional emphasis is usually on technical skills. Regardless of where these courses are housed, graduates working in animation, 3D visualization, and interactive media fields are finding that an ability to apply both technical and creative skills is necessary. This presents challenges in classrooms where students range from the "very artistic/somewhat technical" to the "very technical/somewhat artistic", not least of which is how to assess projects in which both technical and artistic skills must be demonstrated.
\end{abstract}

There is often a negative perception of the critique process as being purely subjective. This "that's-just-the-teacher's-opinion" perception often becomes the stopping point in attempts to get students to recognize critique as part of an iterative development of a design solution. How we handle this assessment can be the difference between a student seeing critique as truly constructive criticism, or merely a matter of opinion.

This researcher has developed a comprehensive method that addresses both objective and subjective criteria while giving students confidence in the validity of the critique. In this method, peer and instructor feedback is given informally as students develop their ideas, and formally at project completion with a traditional class critique. This is followed by completion of an on-line form incorporating Rikert scales and comment fields for specific criteria. Works being evaluated are also posted so students can view each piece as they complete the form. Results are compiled into a database, and a password protected report is automatically generated for each student showing the average ranking for each question and compiled comments. Anonymity is preserved, allowing students a comfortable way to provide honest feedback to classmates. Students can use this report to guide revisions to their work, and the instructor can use it to evaluate how the class, and each student, understands the principles being taught, and how their abilities to think critically are developing.

By tracking averages of student evaluations over several years, it has been found that peer feedback and instructor feedback closely correlate, providing affirmation of the critique to the student, and support for the final grade.

\section{Creative Critique vs. Objective Scoring}

Critique is the traditional means used to provide constructive analysis and advice to students. The typical process involves in-class discussion where everyone present has an opportunity to offer verbal feedback intended to help each student understand how well their work demonstrates skills they are learning. ${ }^{\mathrm{i}}$

In many digital media courses offered in art departments, the instructional emphasis is weighted heavily toward the creative. In these courses, traditional in-class critique of creative assignments 
is expected by the student as this is the norm in every art class they take. Critique in this situation is subjective in that there may be many solutions to a design problem. Every student's solution will be different, and there is no one right answer. Discussion in the critique is intended to help the students understand the relative strengths and weaknesses of how design principles were applied to the work presented, and to encourage them to explore options to improve the solution.

Since instruction on software and technical skills in art departments is often limited, scoring on these skills is secondary to the creative in critique. The score on a project may include a small percentage for technical merit based less on whether the student can perform particular "tasks" and more on whether poor application of technical skills has negatively impacted the visual result. Scoring in this case can be very subjective and can differ somewhat from instructor to instructor. Even in art courses where the students are used to this kind of evaluation, students will still complain that the instructor is just offering opinion and not concrete evidence for assigning a grade - particularly if they do not agree with the instructor. Peer evaluation during the in-class critique will usually help to support the instructor's comments in cases where the class is accustomed to the critique process and where everyone participates fully in the discussion. This becomes a bit more problematic in beginning courses, or when a particular class has a high percentage of "non-participators."

In courses offered in many technical programs, instruction is more heavily weighted to learning software and technical skills with less emphasis placed on creative application. Scoring in these courses are often more objective, with points given for accomplishing each particular task required by the assignment. Creative aspects of an assignment are evaluated by a traditional critique process in most cases, but the percentage of the score for design and creativity will not be as high. This percentage, even though smaller than the technical, may serve to adjust the final score enough so that students will "blame" this loss of a letter grade or more on the instructor's opinion. This is particularly true in courses where design principles are not emphasized strongly enough to help students develop strong criticism skills, putting the burden of providing feedback on the instructor.

Having taught in both types of programs, this researcher has observed even less acceptance of the "subjective critique" from students in the technical programs than from those in art departments, in part because it has not been as much a part of their educational experience. ${ }^{\mathrm{ii}}$

Digital media, as an industry, is relatively new, and instructional programs to train the artists and technical staff needed are even newer. As the industry has matured, it has become evident that a good balance between artistic and technical skills will be required from future digital media professionals. Instructional programs are responding to the needs of this growing industry and are beginning to develop and apply best practices for instruction that can provide this balance.

In the Digital Media Program (DIGM) at East Tennessee University (ETSU), located in the Department of Technology \& Geomatics, courses have been recently redesigned to include both creative and technical content in a more balanced proportion. Because we are in an engineering technology department rather than in an art department, many of the students who come to the program do not consider themselves to be "artists" first, and tend to put less value on the creative aspects of the courses than on the technical. The "that's just the teacher's opinion" complaint has 
been a common response to critique in this program. How we handle the less concrete parts of our assessment can be the difference between a student seeing a critique as merely a matter of opinion, or as truly constructive criticism.

In an attempt to make the critique process more effective-and more evidently valid-for these students, a method of project assessment that addresses both objective and subjective criteria while giving students confidence in the validity of the critique has been developed This method combines traditional critique with objective scoring and peer corroboration.

\section{The Method}

In this method, critique becomes part of the evaluation process in an iterative way, similar to the process of creating and revising work in a work situation. Peer feedback is given informally in concept critiques as student develop their ideas, and formally at the end of the project with a traditional in-class critique and an online critique.

Goals for critique throughout the process are as follows:

- To identify aesthetic and creative strengths of the solution to the assigned problem,

- give students practice identifying problems and proposing possible solutions,

- help students develop critical analysis skills in evaluating their work and the work of others,

- give students practice defending their work by using knowledge of appropriate principles of design and communication as support for their solutions, and

- give students opportunities to apply feedback from critiques toward improving the work.

When a project is assigned, students are given a detailed document describing project parameters (Appendix 1). Included is a "guidelines" page outlining considerations for assessing design principles and what to look for when evaluating technical aspects of the project (Appendix 2). They are also given a copy of the survey that they will complete as part of an online critique (Appendix 3) and a score sheet specifying point breakouts for the project criteria (Appendix 4). These will be somewhat different for each project depending upon the specific objectives for the project. Because some parameters of a project are more concrete, the score sheet can be used as a checklist by the student for confirming that all conditions have been met. Providing these documents at the beginning of an assignment lets students know up front how grades will be assigned.

The iterative assessment and revision process throughout the assignment generally proceeds as follows:

1. Brainstorming and feedback on initial ideas, and on sketches, storyboards, or other previsualization

2. Informal feedback by the instructor and the class during production

3. In-class critique on the finished project

4. Online critique assigned as homework

5. Report generated from the online critique

6. Revision of the project based on feedback 
7. Final grade and instructor feedback, including scores for both technical and creative criteria.

In the "brainstorming and feedback" phase, students present conceptual ideas (usually more than one) for the project to the class, accompanied by sketches, storyboards or other types of previsualization. Each student will describe to the class how and/or why they think the ideas solve the problem presented by the assignment. The student's classmates and the instructor offer feedback on the conceptual solutions and the visual presentations, make suggestions, and help brainstorm ways to push weaker ideas toward more creative solutions. Students then choose the final direction they will take toward solving the problem, and make revisions to the idea and previsualizations. During production, students are encouraged to seek feedback from their peers as they work in class and during lab times. The instructor also makes periodic checks on progress and provides one-on-one feedback on both creative and technical issues.

As students near completion of an assignment, a traditional in-class critique is scheduled. Each student presents the completed project, discusses the rationale for the concept solution and explains how their design supports the message or purpose of the work.

The first three stages of the critique process described above are typical of most courses in which critique is part of a project assessment process. In many cases, the process stops here and a grade is assigned. In other cases, students have an opportunity to revise projects based on the critique before it is submitted for a grade. This works reasonably well, but it does not provide a record of the critique, either for specific comments made, or who actually contributed to the discussion. Students will generally only remember the instructor's comments as they relate to the grade.

In this modified method, an online critique is assigned as homework immediately after the inclass critique. Students provide the instructor with small, JPEG-formatted graphic files of their work, or links to the course server, which are posted on Blackboard. Students use these to refer back to the work as they complete an on-line survey form incorporating Rikert scales and comment fields for specific subjective criteria for each work being evaluated.

To accomplish this, phpESP, an open source, easy-to-use software package for creating, deploying and managing web surveys is used. With phpESP, you can create a survey through a web interface without having to download or install software. PhpESP allows you to make surveys with standard question types, including text, radio buttons, check boxes and drop-down lists. PhpESP can also handle questions rating multiple statements along a common numeric (Rikert) scale.

Response data is collected in a mySQL database, and a password protected report is immediately generated for each student showing the average of the ranking for each question and all of the comments. Anonymity of the authors is preserved, allowing students a comfortable way to provide honest and direct feedback to their fellow classmates. This report can be used by students to guide revisions to their work prior to turning it in for a final grade.

In the on-line critique, students have time to think about information brought up in the in-class critique which can help inform their feedback and comments written on the forms are often more 
thorough than in the in-class critique. By having them write comments, their critical analysis skills are reinforced. Also, everyone in the class fully participates in the evaluation process.

By having a database of critique results, the instructor can get a sense of how well both the class and each student understand the principles by which the criteria are derived. The instructor can use the same instrument when doing the final evaluation, reducing time spent grading and commenting on each project.

Purely objective criteria, such as identified technical skills that must be demonstrated and adherence to specific instructions, are scored separately from the more subjective criteria in score sheets prepared by the instructor. Technical application is also discussed in critique as necessary to guide the student to successful completion of the project.

This survey portion of this method does not require the use of an online form, however the phpESP survey does save a lot of the time that would be required if the survey results were compiled manually. It also provides for more immediate response to the student. Without an automated process, it is impractical to try to give students results prior to their revision phase.

\section{Conclusion}

By tracking averages of the rankings given by the students over several years of using this method in a variety of projects, it has been found that student averages and independent rankings assigned by the instructor closely correlate.

When this method was implemented using printed paper surveys, students rarely got their results back from the class until after a grade had been assigned due to the length of time it took to collate and record the results. Students got very good feedback, but were not able to apply it in time to make revisions. When revising projects, they had to depend upon their memory of comments made during the in-class critique. Even so, on elements of the scoring where both class members and the instructor provided feedback, students scored their peers within a $1 / 2$ letter of the grade assigned by the instructor over $73 \%$ of the time. ${ }^{\text {iii }}$ These results were based on scoring data gathered from fall 2002 through fall 2005 in Raster-based Imaging classes where this method was used for two to three projects per class ( 5 projects assessed per year). The projects assessed were a Photoshop image compositing project, a poster design project, and a digital painting project. Similar results were found for each of the individual projects. ${ }^{\text {iv }}$

Results were better using the online surveys since feedback was faster, allowing students to apply the results of the survey to project revisions prior to turning in their work for final scoring. In over $86 \%$ of projects over the 2 -semester period in which the online survey was used, students scored their peers within a $1 / 2$ letter of the grade assigned by the instructor. This data was gathered from Spring 2006 and Fall 2006 in the same classes, and on the same projects, as before. In the 5 project instances that were evaluated, the overall results were better. Results will continue to be tracked to see if this remains consistent. 
There has been a notable decrease in the number of challenges to grades assigned for these types of projects by this researcher, ${ }^{\mathrm{v}}$ indicating that the corroboration between student evaluation and instructor evaluation has provided an affirmation of the critique to the student, and support for the final grade given.

Other factors outside of the classroom, such as scholarships which can be lost if a student's GPA drops, have also made it necessary for instructors to find ways to defend assigned grades on appeal where evaluation is perceived by the student to be subjective. This method provides a good record helping to establish evidence of instructor objectivity.

\section{References}

1. Barrett, Terry, 1988. A Comparison of the Goals of Studio Professors Conducting Critiques and Art Education Goals for Teaching Criticism, Studies in Art Education, Vol. 30, No. 1 (Autumn, 1988), pp. 22-27

2. Patton, Angela, 2002, Chindogu: A Problem Solving Strategy for Transforming Uselessness into Fearlessness, Proceedings of the 2002 ASEE Gulf-Southwest Annual Conference, The University of Louisiana at Lafayette, March 20-22. Retrieved December 15, 2006 from: http://engr.louisiana.edu/asee/proceedings/IA2.pdf

3. Roland, Craig, ed., 2001. It's the Thought That Counts, Fostering Student Thinking in the Art Classroom, handout presented at the National Art Education Association Conference in New York on March 16, 2001. Retrieved December 2, 2006 from: http://www.arts.ufl.edu/ART/rt_room/teach/itsthethought1.pdf

4. Rush, Jean C. 1989. Coaching by Conceptual Focus: Problems, Solutions, and Tutored Images, Studies in Art Education, Vol. 31, No. 1 (Autumn, 1989), pp. 46-57. 


\section{Assignment: Ballistic Expose 4 Competition}

For this assignment, you will be entering the Ballistic Expose 4 Competition. Please review the website for Call for Entries information. http://www.ballisticpublishing.com/books/expose4/

In this assignment you will follow the competition guidelines and you will be graded not only on the aesthetic and technical quality of your work, but on how well you follow the instructions for entry and other competition guidelines.

The illustration must communicate a story, message or concept.

Both creative and technical aspects of this project will be assessed.

This project will run concurrently with other projects, so plan your time accordingly.

Tue. Jan. $24 \quad$ Sketches and Concept statements due.

Be prepared to present your ideas to the class. See Homework \#1.

Tue., Jan. $31 \quad$ Revised Sketches and Concept statements due.

Thu., Feb. 23 Critique (digital files only)

You will be doing an online critique on each image submitted for homework tonight. Compiled comments will be available to you tomorrow.

Mon., Feb. 27 Revisions made and digital files due.

Digital files must be uploaded by midnight to the Expose site. Any assignment not turned in to the site by the deadline will be considered late and will receive a 1 letter grade penalty.

Thur, Mar. $2 \quad$ Matted prints due.

The best images will be displayed in the DMC gallery.

Instructions for the Assignment:

1. Before you start, plan out your idea, write a concept statement, and create a sketch (or several sketches) that will serve as your "blueprint" for the piece.

As you do this, you should be making production notes, shot lists, gathering reference images (textures, art showing the style you are exploring, photos you may want to useas a composite part of the illustration, or as reference for form, lighting, color, or composition), and other items used for inspiration.

After presenting your sketches and ideas to the class, take the feedback from the session and make revisions to your sketch. The instructor must sign off on your sketch prior to production. You will turn this sketch in on Feb. 23 with your final illustration. 
2. Adhere to the size and resolution specifications in the competition guidelines:

- Image dimensions should be print resolution (as large as you can possibly render). Do not send in a low-resolution placeholder and ask us to get back to you, as we won't.

- A guideline is 2657 pixels wide and/or 3636 high, 300 DPI (portrait), or 3636 pixels wide and/or 2657 pixels high, 300 DPI (landscape). Your image aspect ratio and layout will dictate the final resolution. These are given as guidelines. To be safe, render images that are larger than these specified

- DO NOT upsample your images to achieve higher resolution. If you cannot reach the desired full-page resolution, just send in what you have.

Note: it is not a bad idea to work a little larger than your intended final size. You can render your image with more detail and drop your image size down before you submit the work to Expose.

3. When your image is nearly complete, you may want to upload it for critique at any of the various portal sites (see list in syllabus and on Blackboard). It is always a good idea to get feedback before you submit your work to a competition.

Final presentation and preparation:

Matte your final image using black (white core) matte board so you will have a slight white frame from the window bevel. Use matte board, NOT foam core, for the back mount board. Prepare the matte to the following specifications:

- 2" margin on the left, right and top. 3" margin on the bottom.

- There must be a cover sheet that covers exactly the entire board, and is flapped over and taped on the back. Use black medium weight paper or vellum. See classroom example.

It is a good idea to have the mattes professionally done.

\section{Grading Criteria:}

- I will be grading from the printed image and from the file. The printed images must be as perfect as possible. Expect to print several test images until you are satisfied.

- Selections, compositing, cloning, and other technical skills must be properly applied and well-crafted.

- Images must tell a story.

- Images must demonstrate good application of principles of design for color, composition, etc. An in-class and online critique will assist you in identifying problems and successes in the more "subjective" aesthetic and creative parameters of this project.

- All instructions must be followed to the letter.

- Measurements must be correct.

- Mounting must be professional in appearance—clean and neat—and all cuts must be precise. 


\section{Appendix 2: Critique Guidelines given to students prior to first critique}

\section{Consider the following as you assess the projects:}

(These are points to consider when critiquing your and others work)

1. Did it tell a story or clearly communicate an idea?

The image should be more than just a pretty picture. Everything in the picture should contribute to the overall idea. There should be no image elements that are just "decoration" or arbitrary elements for style purposes only that don't support the overall idea.

2. Was the work well-crafted-not sloppy? Do you see artifacts (clone patterning, pixels left from bad selections, colors and tonal ranges of individual images that are not balanced to each other), resolution problems, or other tell-tale indications that the image-making techniques used were applied improperly?

3. How creative and original was the solution to the problem?

Was it memorable (in a good way)? Was it an original idea or was it like other things you've seen before (done to death)?

There should be a conceptual solution to the problem-an identifiable IDEA. Did it surprise you and make you think: "I wish I'd thought of doing it that way!" or "What a good way to get across that message?"

5. Do all of the elements fit well into the environment? Do shadows look natural, fitting expected density, color, length and shape for the properties of the light represented in the image? Is the light in the image coming from a consistent direction as indicated by the constructed shadows and highlights? Is the perspective working correctly for all of the elements?

6. Does the composition work to lead your eye appropriately around and through the image?

4. Was the project complete according to the instructions and ready for presentation?

Does it look finished, or does it seem to be merely a work in progress?

Please think of comments you might make that might be helpful to the artist. (a way to improve the project or presentation). 


\section{Appendix 3: PhpESP Survey for the sample assignment}

\section{On-Line Critique: Ballistic Project}

Please rank the project on how well it met the criteria expressed for each question. Make comments where appropriate. "10" is good. "1" is bad.

Questions marked with a * are required.

$* 1$.

Your name:

*2. When compared to the completed image, did the artists' statement do a good job of describing the intent of the piece, and explaining the artist's rationale for the idea or technique? Does it make sense when related to the image?

$\mathbf{1 =}$ "confusing/rewrite!!", $\mathbf{1 0 =}$ =very informative!!"

$\begin{array}{rrrrrrrrrrr}1 & 2 & 3 & 4 & 5 & 6 & 7 & 8 & 9 & 10 \\ \text { Rating } \mathbf{C} & \mathbf{C} & \mathbf{C} & \mathbf{C} & \mathbf{C} & \mathbf{C} & \mathbf{C} & \mathbf{C} & \mathbf{C} & \mathbf{C}\end{array}$

3. Comments for above question:

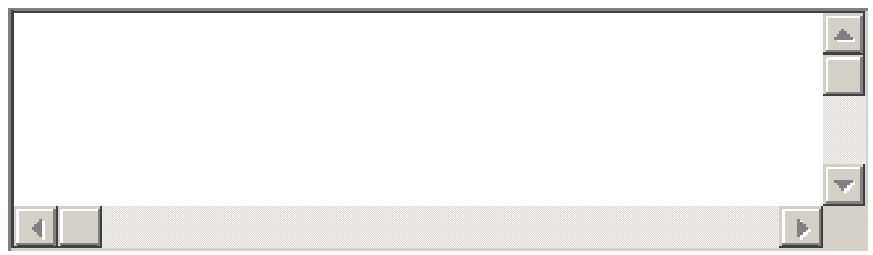

*4. Was the work well-crafted—not sloppy? Do you see identifiable image problems indicating more work is needed--clone patterning, pixels left from bad selections, colors and tonal ranges of individual images that are not balanced to each other or other tell-tale indications that Photoshop has been applied to the image improperly? Illustration must demonstrate good raster-based imaging skills. $\mathbf{1}="$ terrible", $\mathbf{1 0}="$ very well-crafted!!" 
$\begin{array}{rrrrrrrrrrr}1 & 2 & 3 & 4 & 5 & 6 & 7 & 8 & 9 & 10 \\ \text { Rating } \mathbf{C} & \mathbf{C} & \mathbf{C} & \mathbf{C} & \mathbf{C} & \mathbf{C} & \mathbf{C} & \mathbf{C} & \mathbf{C} & \mathbf{C}\end{array}$

5. Comments for above question:

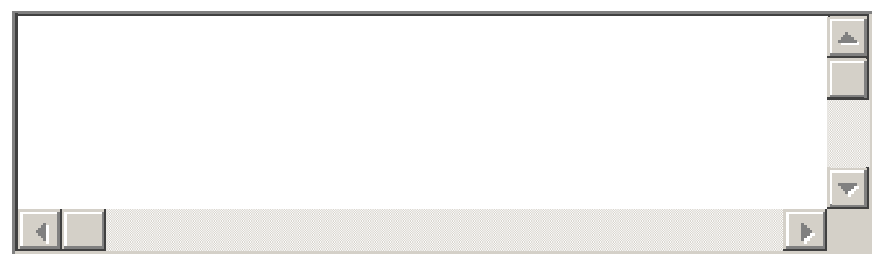

*6. Do all of the image elements, including color and style, support the overall idea?

Everything in the picture should contribute to the overall idea, mood and intent of the image.

$\mathbf{1 = " n o t ~ v e r y ~ w e l l " , ~} \mathbf{1 0 =}$ =fabulous!!"

\begin{tabular}{rr|r|r|r|r|r|rrrr}
1 & 2 & 3 & 4 & 5 & 6 & 7 & 8 & 9 & 10 \\
Rating & $\mathbf{C}$ & $\mathbf{C}$ & $\mathbf{C}$ & $\mathbf{C}$ & $\mathbf{C}$ & $\mathbf{C}$ & $\mathbf{C}$ & $\mathbf{C}$ & $\mathbf{C}$ & $\mathbf{C}$
\end{tabular}

7. Comments for above question:

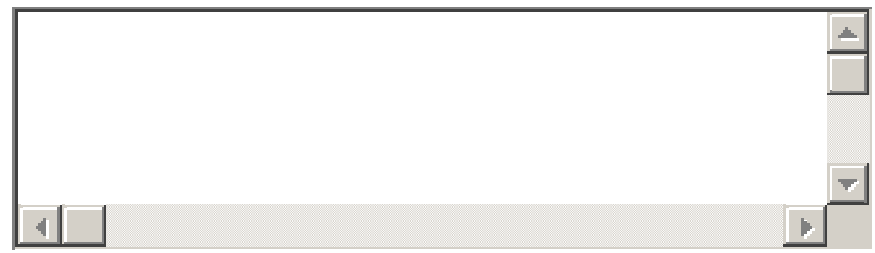

*8. Does the composition work to lead your eye appropriately around and through the image?

$\mathbf{1 = " p o o r l y ~ c o m p o s e d " , ~ 1 0 = " f a b u l o u s ! ! " ~}$

\begin{tabular}{|c|c|c|c|c|c|c|c|c|c|}
\hline 1 & 2 & 3 & 4 & 5 & 6 & 7 & 8 & 9 & 10 \\
\hline $\operatorname{ting} \mathbf{C}$ & $\mathbf{C}$ & $\mathbf{C}$ & C & C & C & $\mathrm{C}$ & C & C & C \\
\hline
\end{tabular}


9. Comments for above question:

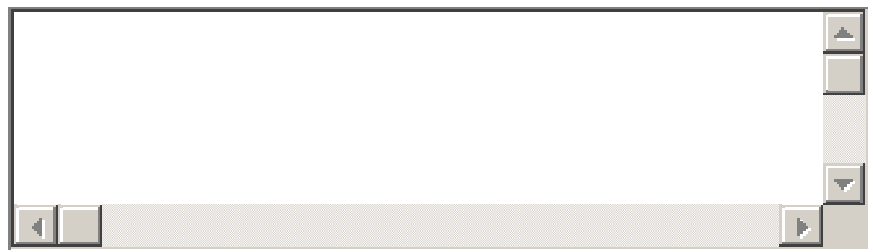

*10. How well did the color fit the mood or theme of the piece. Does the image have an attractive and/or appropriate color scheme?

$\mathbf{1}=$ "Just didn't do it for me", $\mathbf{1 0 =}$ =fabulous!!"

\begin{tabular}{r|r|r|r|r|r|r|r|r|r}
1 & 2 & 3 & 4 & 5 & 6 & 7 & 8 & 9 & 10 \\
Rating $\mathbf{C}$ & $\mathbf{C}$ & $\mathbf{C}$ & $\mathbf{C}$ & $\mathbf{C}$ & $\mathbf{C}$ & $\mathbf{C}$ & $\mathbf{C}$ & $\mathbf{C}$ & $\mathbf{C}$
\end{tabular}

11. Comments for above question:

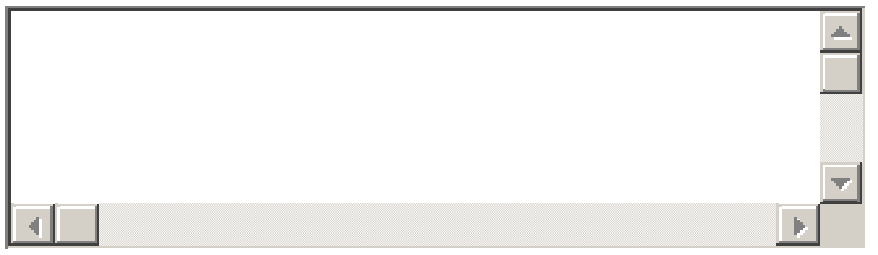

*12. How creative and original was the image? Was it memorable (in a good way)? Did it surprise you and make you think "I wish I'd thought of doing it that way!" or was the idea "done to death?"

$\mathbf{1 =}$ "Just didn't do it for me", $\mathbf{1 0 =}$ =fabulous!!"

\begin{tabular}{|c|c|c|c|c|c|c|c|c|c|}
\hline 1 & 2 & 3 & 4 & 5 & 6 & 7 & 8 & 9 & 10 \\
\hline ing $\mathbf{C}$ & C & $\mathbf{C}$ & C & C & $\mathbf{C}$ & C & C & $\mathrm{C}$ & C \\
\hline
\end{tabular}

13. Comments for above question: 
*14. How would you judge the level of difficulty of project attempted?

$\mathbf{1}=$ "extremely easy", $\mathbf{1 0}="$ difficult to do"

$\begin{array}{rrrrrrrrrrr}1 & 2 & 3 & 4 & 5 & 6 & 7 & 8 & 9 & 10 \\ \text { Rating } \mathbf{C} & \mathbf{C} & \mathbf{C} & \mathbf{C} & \mathbf{C} & \mathbf{C} & \mathbf{C} & \mathbf{C} & \mathbf{C} & \mathbf{C}\end{array}$

15. Comments for above question:

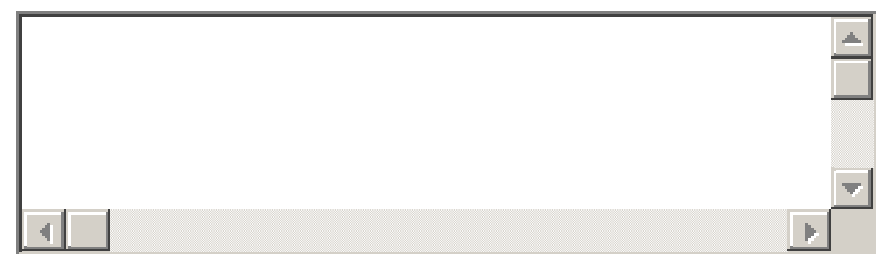

*16. Does the resolution seem to be high enough for good image detail? $\mathbf{1}=$ "bad image detail", $\mathbf{1 0}="$ fabulous!!"

\begin{tabular}{r|r|r|r|r|r|r|r|r|r}
1 & 2 & 3 & 4 & 5 & 6 & 7 & 8 & 9 & 10 \\
Rating $\mathbf{C}$ & $\mathbf{C}$ & $\mathbf{C}$ & $\mathbf{C}$ & $\mathbf{C}$ & $\mathbf{C}$ & $\mathbf{C}$ & $\mathbf{C}$ & $\mathbf{C}$ & $\mathbf{C}$
\end{tabular}

17. Comments for above question:

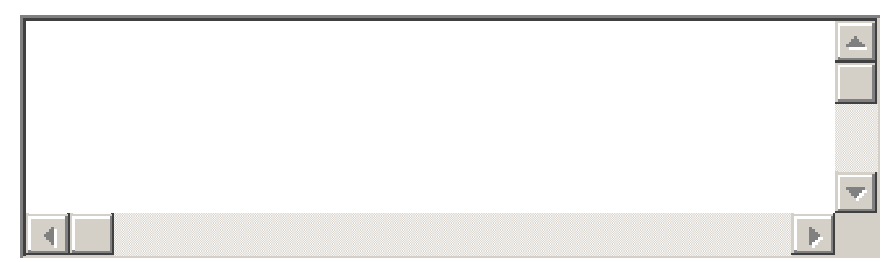

*18. Do you think this illustration needs additional revisions to be a great portfolio piece? $\mathbf{1}=$ "desperately needed", $\mathbf{1 0}=$ "don't touch it!!"

$\begin{array}{rrrrrrrrrrrr}1 & 2 & 3 & 4 & 5 & 6 & 7 & 8 & 9 & 10 \\ \text { Rating } \mathbf{C} & \mathbf{C} & \mathbf{C} & \mathbf{C} & \mathbf{C} & \mathbf{C} & \mathbf{C} & \mathbf{C} & \mathbf{C} & \mathbf{C}\end{array}$


19. Comments for above question:

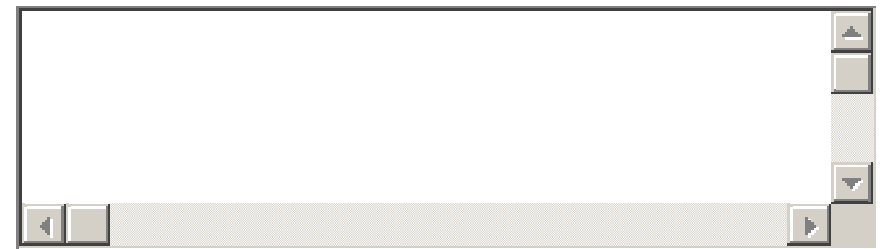

*20. Did it tell a story or clearly communicate an idea?

$\mathbf{1}=" I ' m$ confused", $\mathbf{1 0}=$ "very clear"

\begin{tabular}{|c|c|c|c|c|c|c|c|c|c|}
\hline 1 & 2 & 3 & 4 & 5 & 6 & 7 & 8 & 9 & 10 \\
\hline ting $\mathbf{C}$ & C & C & C & E & C & C & C & C & C \\
\hline
\end{tabular}

21. Comments for above question:

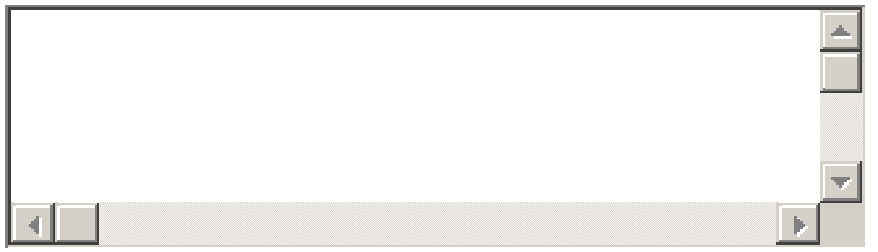

22. Please write an additional comment that might be helpful to the artist (a way to improve the project or presentation).

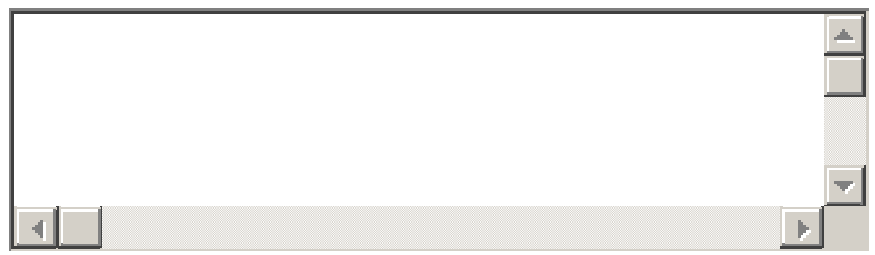


Appendix 4: Report generated by phpESP, showing the results for one student from the online critique for the sample assignment.

\section{Critique: Ballistic Project}

Please rank the project on how well it met the criteria expressed for each question. Make comments where appropriate. "10" is good. " 1 " is bad.

\section{Your name: \\ \# $\quad$ Response \\ 1 andy wade \\ 1 Andy Woods \\ 1 Brandon Guimond \\ 1 brianowell \\ $1 \quad$ Emilee Fitch \\ $1 \quad$ Eric \\ 1 Jason Hendrickson \\ 1 Jeremy \\ 1 Jodi Crabtree \\ 1 Josh Bartlam \\ 1 Justin Cannaday \\ $1 \quad$ Kristen Gramberg \\ 1 MattCantrell \\ 1 Rebecca Stemac}

2. When compared to the completed image, did the artists' statement do a good job of describing the intent of the piece, and explaining the artist's rationale for the idea or technique? Does it make sense when related to the image?

$1={ }^{\prime}$ confusing/rewrite!!", 10="very informative!!"

Average rank

Rating

$$
\begin{array}{llllllllll}
1 & 2 & 3 & 4 & 5 & 6 & 7 & 8 & 9 & 10
\end{array}
$$

3. Comments for above question:

\section{\# Response}

1 Definitely helps to understand the image after I read it. Got it without the statement though. 
1 Holds well to the description.

1 Looks like the statement and the image match well.

1 I love the idea for this. Expressed very well.

1 nice statement

1 Very clear statement, piece really stated what is shown clearly.

4. Was the work well-crafted-not sloppy? Do you see identifiable image problems indicating more work is needed--clone patterning, pixels left from bad selections, colors and tonal ranges of individual images that are not balanced to each other or other tell-tale indications that Photoshop has been applied to the image improperly? Illustration must demonstrate good raster-based imaging skills.

$1={ }^{\prime \prime}$ terrible", 10="very well-crafted!!"

$$
\begin{aligned}
& \text { Average rank } \\
& \begin{array}{llllllllll}
1 & 2 & 3 & 4 & 5 & 6 & 7 & 8 & 9 & 10
\end{array}
\end{aligned}
$$

Rating

5. Comments for above question:

\section{\# Response}

1 liked the photos used. Some technical problems with the compositing.

1 Looks much better than the first one presented in class!

1 The facial part looks too plastered on. Not believable.

1 The added bit of face doesn't seem to blend well with the picture.

1 The old part of the face doesn't match the lighting as well as it should, and it doesn't really look like she's holding a piece of her face.

1 The piece she is holding has some compositing artifacts around it.

1 Very nicely done

6. Do all of the image elements, including color and style, support the overall idea? Everything in the picture should contribute to the overall idea, mood and intent of the image.

$1=$ "not very well", 10="fabulous!!"

Rating

Average rank

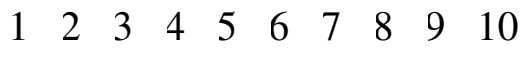

7. Comments for above question: 


\section{\# Response}

1 Maybe you could use cooler colors to show a "bad" person. Otherwise, color scheme seems appropriate.

1 Needs a little bit more of an edge around the peeling of the face. A little more shadow and highlight

1 She still seems to have a bit of red-eye. Some of the stuff in the picture doesn't seem to be necessary-clutters the image.

1 The style and pose of the picture really fits and supports the overall idea and point of the piece.

8. Does the composition work to lead your eye appropriately around and through the image?

$1=$ "poorly composed", 10="fabulous!!"

Average rank

$\begin{array}{llllllllll}1 & 2 & 3 & 4 & 5 & 6 & 7 & 8 & 9 & 10\end{array}$

Rating

9. Comments for above question:

\section{\# Response}

1 Focus stays mainly on the face. Good.

1 I like the way her hand guides the eye down through the image.

1 I think the reflection should be farther to the right. It's too centered right now. Draws too much attention to an unimportant part.

1 Lights around the mirror give good motion. The angle looks good.

1 The lights on each side of the picture really keep your eye onto the center of the page on her, which is good since she's the main focal point.

1 You're right about not using a straight on shot. The angle is more dynamic.

10. How well did the color fit the mood or theme of the piece. Does the image have an attractive and/or appropriate color scheme?

1="Just didn't do it for me", 10="fabulous!!"

Average rank

$$
\begin{array}{llllllllll}
1 & 2 & 3 & 4 & 5 & 6 & 7 & 8 & 9 & 10
\end{array}
$$

Rating

11. Comments for above question:

\# Response 
1 Good color choices.

1 The lights and the colors of the lights really bring out the point of the piece well, and adds to the overall idea.

1 Very warm colors give a good mood of happiness and comfort. The colors in the peeling of the face look a little off. They need to be cooler to give more of weary and frail feel.

12. How creative and original was the image? Was it memorable (in a good way)? Did it surprise you and make you think "I wish I'd thought of doing it that way!" or was the idea "done to death?"

1="Just didn't do it for me", 10="fabulous!!"

Average rank

Rating

13. Comments for above question:

\section{\# Response}

1 Creative idea!

1 I think I've seen this idea a few times before.

1 I've seen a few paintings like this and it's a tad cliche.

1 Seen this kind of thing before.

1 The peeling of the face seems to be done before but you pulled it off well.

1 Unique idea.

14. How would you judge the level of difficulty of project attempted?

$1={ }^{\prime}$ extremely easy", 10="difficult to do"

Average rank

$$
\begin{array}{llllllllll}
1 & 2 & 3 & 4 & 5 & 6 & 7 & 8 & 9 & 10
\end{array}
$$

Rating

15. Comments for above question:

\section{\# Response}

1 A lot of masking it seems. Took lots of time.

1 Getting the old woman pieces on the face to blend into the actual "real" face could be very difficult to do correctly. 


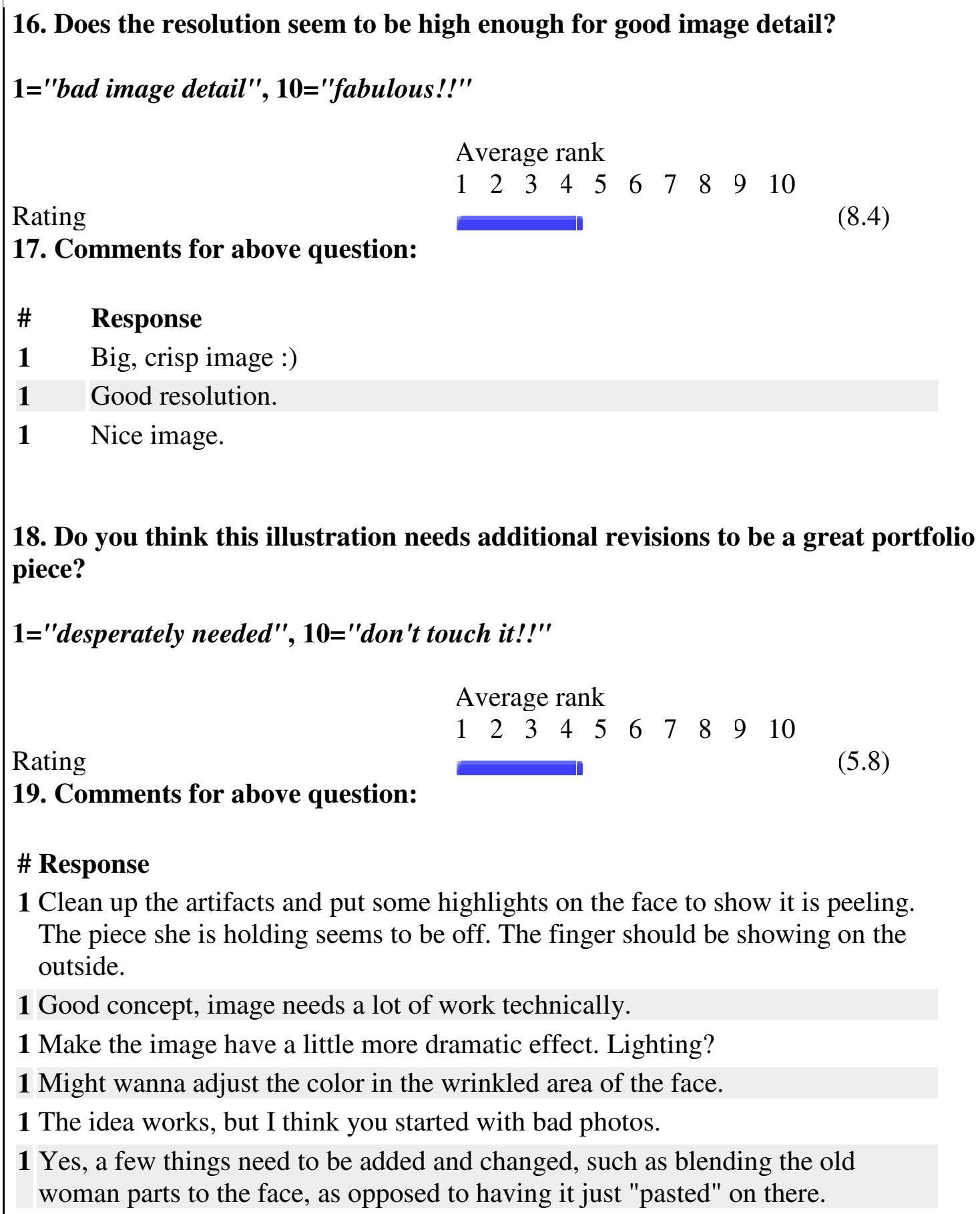

18. Do you think this illustration needs additional revisions to be a great portfolio piece?

$1=$ "desperately needed", 10="don't touch it!!"

Average rank

Rating

19. Comments for above question:

\section{\# Response}

1 Clean up the artifacts and put some highlights on the face to show it is peeling. The piece she is holding seems to be off. The finger should be showing on the outside.

1 Good concept, image needs a lot of work technically.

1 Make the image have a little more dramatic effect. Lighting?

1 Might wanna adjust the color in the wrinkled area of the face.

1 The idea works, but I think you started with bad photos.

1 Yes, a few things need to be added and changed, such as blending the old woman parts to the face, as opposed to having it just "pasted" on there.

20. Did it tell a story or clearly communicate an idea?

$1={ }^{\prime I}$ 'm confused", 10="very clear" 


Average rank
Rating
21. Comments for above question:
\# Response
1 I can easily read what the point of this piece is. No problems at all.
1 I get the story from the image.
1 The message was pretty clear. Stands alone well without the artist statement.
22. Please write an additional comment that might be helpful to the artist (a way
to improve the project or presentation).
\# Response
1 I really like the idea! The wrinkled face needs to fit in with the image better, it
looks like it was just stuck on there instead of being under her skin and some
more cracks might help as well.
1 Just clean up the image a little bit and it should be a good piece.
$\mathbf{1}$ Work on some of the technical aspects. I can see artifacts from the compositing
and cloning.

$\underline{\text { Go back to Management Interface }}$ 
Appendix 5: Grade sheet used for the sample assignment

\section{Ballistic Expose 4 Competition}

Student:

Grade:

The grade was determined by the critique score and adjusted by the execution of additional elements as indicated below.

Score for my critique:

See attached critique sheet* for comments. This is your base grade. This score will be decreased by the amount of points indicated for the items below if instructions were not followed or if specific technical details were not accomplished.

*the same form used by the class in your online critique.

Project deadlines (5 points each):

Did you turn in a completed sketch in by $1 / 31$ ?

Did you have a completed project ready for critique by $2 / 18$ ?

Did you turn in the revised project by $2 / 23$ ?

Did you download the completed project file to the Ballistic website by $2 / 23$ ?

Final presentation and preparation for exhibition (10 points):

Matte your final image using black (white core) matte board. Prepare the matte to the following specifications:

2" margin on the left, right and top. 3" margin on the bottom. (4 points)

There must be a cover sheet that covers exactly the entire board, and is flapped over and taped on the back. Use black medium weight paper or vellum. See classroom example. (3 points)

The matte must be neat with no smudges, pencil marks or imprecise cuts. ( 3 points)

File must meet ALL requirements of the competition (10 points):

If this was not correct, it would not meet the basic instructions for the assignment. If the file did not meet competition requirements it was disqualified by Ballistic Publishing.

300 PPI, uncompressed RGB TIFF (.TIF) file format.

Do not include Alpha or other non-RGB channels or layers.

\section{Additional comments:}


${ }^{\mathrm{i}}$ Traditional art project critique methods discussed throughout this paper are as taught to the author at the University of Georgia and Syracuse University, and co-practiced with faculty colleagues in several educational programs. The goals that are outlined in the method proposed are drawn from these experiences. Supporting information for critique processes as traditionally applied can be found in several resources, including Successful Art Class Critique, by Marvin Bartel; Coaching by Conceptual Focus: Problems, Solutions, and Tutored Images, by Jean Rush, 1989; and It's the Thought That Counts!, by Craig Roland, 2001.

${ }^{i i}$ Support for this can be found in Chindogu: A Problem Solving Strategy for Transforming Uselessness into Fearlessness, by Angela Patton, 2002

iii Final grades actually assigned were adjusted by non-subjective criteria

iv The stated result was the average of the scoring results from all three projects. Individual project results were similar.

${ }^{\mathrm{v}}$ Based on over 10 years experience teaching assignments involving critique of creative skills. 